\title{
Customization of an Open-Lung Ventilation Strategy to Treat a Case of Life-Threatening Acute Respiratory Distress Syndrome
}

\author{
David A Grooms RRT, Stephen H Sibole RRT, James R Tomlinson MD, \\ Paul E Marik MD, and Robert L Chatburn MHHS RRT-NPS FAARC
}

\begin{abstract}
The ARDS Network low-tidal-volume protocol is considered the standard of care for patients with acute lung injury (ALI) or acute respiratory distress syndrome (ARDS). The protocol is built on the foundation of low-tidal-volume ventilation, use of a combined PEEP and $\mathrm{F}_{\mathrm{IO}_{2}}$ table, and managing alveolar end-inspiratory pressure by limiting the plateau airway pressure to $\leq 30 \mathrm{~cm} \mathrm{H}_{2} \mathrm{O}$. Although this strategy, to date, is the only method that significantly improves ALI/ARDS survival, alternative methods of improving hypoxemia and minimizing ventilator-induced lung injury, in conjunction with low-tidal-volume ventilation, can be used for life-threatening ARDS. We present a case in which we customized the use of alveolar recruitment maneuvers by analyzing the hysteresis of the pressure-volume curve to assess lung recruitability, decremental PEEP to sustain lung recruitment, and careful use of plateau pressure $\geq 30 \mathrm{~cm} \mathrm{H}_{2} \mathrm{O}$, which improved our patient's life-threatening hypoxemia within the first $\mathbf{3 6}$ min of arrival to our ICU. Key words: acute lung injury; acute respiratory distress syndrome; positive end expiratory pressure; PEEP; lung recruitment; fraction of inspired oxygen; pressure-volume curve; ALI; ARDS; optimum PEEP; decremental PEEP trial. [Respir Care 2011;56(4):514-519. (C) 2011 Daedalus Enterprises]
\end{abstract}

\section{Introduction}

Acute respiratory distress syndrome (ARDS) is a lifethreatening condition in which an acute insult to the lungs causes inflammation, alveolar capillary permeability, alveolar flooding, low $\mathrm{P}_{\mathrm{aO}}$, and respiratory distress. ${ }^{1}$ In its most severe form, ARDS is characterized by acute-onset

David A Grooms RRT, Stephen H Sibole RRT, James R Tomlinson MD are affiliated with Sentara Norfolk General Hospital, Sentara Healthcare System, Norfolk, Virginia. Paul E Marik MD is affiliated with Eastern Virginia Medical School, Norfolk, Virginia. Robert L Chatburn MHHS RRT-NPS FAARC is affiliated with the Respiratory Institute, The Cleveland Clinic, and with Lerner College of Medicine, Case Western Reserve University, Cleveland, Ohio.

Mr Grooms has disclosed relationships with Hamilton Medical and Covidien. Mr Chatburn has disclosed a relationship with Dräger, Hamilton Medical, CareFusion, Covidien, Newport, IngMar, and Radiometer America. The other authors have disclosed no conflicts of interest.

Correspondence: David A Grooms RRT, Sentara Norfolk General Hospital, 600 Gresham Drive, Norfolk VA 23507. E-mail: dxgrooms@sentara.com.

DOI: $10.4187 /$ respcare. 00867 hypoxemia $\left(\mathrm{P}_{\mathrm{aO}_{2}} / \mathrm{F}_{\mathrm{IO}_{2}} \leq 200 \mathrm{~mm} \mathrm{Hg}\right)$ with bilateral infiltrates on the chest radiograph and the absence of left atrial hypertension. ${ }^{2}$ Patients with ARDS usually require mechanical ventilatory support.

We present a case where the patient's poor oxygenation was restored by careful implementation of ventilator strategies not currently recommended for routine use, but that share a commonality with open-lung ventilation concepts. $^{3-6}$ Our strategy included:

- Alveolar recruitment maneuvers, with a quasi-static pressure-volume (P-V) curve with an end-inspiratory hold

- Analysis of the P-V curve hysteresis and recruitment volume

- PEEP is set in a decremental fashion following the recruitment maneuver

- Low-tidal-volume (low- $\mathrm{V}_{\mathrm{T}}$ ) ventilation of $6 \mathrm{~mL} / \mathrm{kg}$ predicted body weight (PBW)

- Plateau pressure can be greater than $30 \mathrm{~cm} \mathrm{H}_{2} \mathrm{O}$

We continually adjusted this strategy to improve arterial oxygenation while minimizing ventilator-induced lung injury (VILI). 
Table 1. Ventilator Settings and Blood Gas Values

\begin{tabular}{|c|c|c|c|c|c|c|c|c|c|c|}
\hline & $\begin{array}{l}\text { At } \\
\text { Initiation } \\
\text { of MV }\end{array}$ & $\begin{array}{c}9 \mathrm{~h} \\
\text { After } \\
\text { Initiating } \\
\mathrm{MV}\end{array}$ & $\begin{array}{c}33 \mathrm{~h} \\
\text { After } \\
\text { Initiating } \\
\mathrm{MV}\end{array}$ & $\begin{array}{c}35 \mathrm{~h} \\
\text { After } \\
\text { Initiating } \\
\mathrm{MV}^{*}\end{array}$ & $\begin{array}{l}45 \mathrm{~min} \\
\text { After } \\
\text { Arrival }\end{array}$ & $\begin{array}{l}4 \mathrm{~h} \\
\text { After } \\
\text { Arrival }\end{array}$ & $\begin{array}{l}10 \mathrm{~h} \\
\text { After } \\
\text { Arrival }\end{array}$ & $\begin{array}{l}18 \mathrm{~h} \\
\text { After } \\
\text { Arrival }\end{array}$ & $\begin{array}{l}24 \mathrm{~h} \\
\text { After } \\
\text { Arrival }\end{array}$ & $\begin{array}{l}48 \mathrm{~h} \\
\text { After } \\
\text { Arrival }\end{array}$ \\
\hline Ventilation mode & VC-CMV & VC-CMV & VC-CMV & PC-CMV & PC-CMV & PC-CMV & PC-CMV & PC-CMV & PC-CMV & PC-CMV \\
\hline $\mathrm{V}_{\mathrm{T}}(\mathrm{mL} / \mathrm{kg} \mathrm{PBW})$ & 8 & 6 & 6 & 6 & 6 & 6 & 6 & 6 & 6 & 6 \\
\hline Respiratory rate (breaths/min) & 12 & 20 & 16 & 20 & 20 & 20 & 20 & 20 & 20 & 20 \\
\hline PEEP $\left(\mathrm{cm} \mathrm{H}_{2} \mathrm{O}\right)$ & 5 & 15 & 15 & 15 & 22 & 22 & 22 & 20 & 14 & 12 \\
\hline Plateau pressure $\left(\mathrm{cm} \mathrm{H}_{2} \mathrm{O}\right)$ & 23 & 30 & 30 & 30 & 35 & 34 & 33 & 31 & 27 & 25 \\
\hline $\mathrm{F}_{\mathrm{IO}_{2}}$ & 1 & 1 & 1 & 1 & 1 & 0.7 & 0.6 & 0.6 & 0.5 & 0.5 \\
\hline $\mathrm{pH}$ & 7.44 & 7.45 & 7.34 & 7.17 & 7.22 & 7.32 & 7.27 & 7.26 & 7.35 & 7.45 \\
\hline $\mathrm{P}_{\mathrm{aCO}_{2}}(\mathrm{~mm} \mathrm{Hg})$ & 32 & 28 & 34 & 51 & 45 & 31 & 30 & 41 & 34 & 38 \\
\hline $\mathrm{P}_{\mathrm{aO}_{2}}(\mathrm{~mm} \mathrm{Hg})$ & 124 & 83 & 73 & 54 & 169 & 149 & 81 & 139 & 83 & 80 \\
\hline $\mathrm{P}_{\mathrm{aO}_{2}} / \mathrm{F}_{\mathrm{IO}_{2}}(\mathrm{~mm} \mathrm{Hg})$ & 124 & 83 & 73 & 54 & 169 & 213 & 135 & 231 & 166 & 160 \\
\hline $\begin{array}{l}\text { Respiratory system compliance } \\
\qquad\left(\mathrm{mL} / \mathrm{cm} \mathrm{H}_{2} \mathrm{O}\right)\end{array}$ & 27 & 24 & 24 & 24 & 22 & 30 & 23 & 26 & 32 & 33 \\
\hline $\begin{array}{l}* 1 \text { hour prior to transfer to our facility. } \\
\text { MV = mechanical ventilation } \\
\text { VC }=\text { volume control } \\
\text { PC }=\text { pressure control } \\
\text { CMV = continuous mandatory ventilation } \\
\text { PBW = predicted body weight }\end{array}$ & & & & & & & & & & \\
\hline
\end{tabular}

\section{Case Report}

A 33-year-old, 160-cm, $90 \mathrm{~kg}$ (body mass index $35 \mathrm{~kg} /$ $\mathrm{m}^{2}$ ) female was admitted to an outside hospital for dehydration and malnutrition, after presenting to the emergency department with a general feeling of weakness. Her medical history included a Roux-en-Y gastric bypass procedure 11 years prior to this admission. She presented with progressive history of malabsorption (albumin $1.2 \mathrm{~g} / \mathrm{dL}$ ), constipation, rectal prolapse, anemia (hemoglobin $11 \mathrm{~g} /$ $\mathrm{dL}$, hematocrit 33\%), and shortness of breath. She was also non-responsive to empirical antibiotics and steroids as an out-patient. She had developed oral thrush with current steroid use and had stopped eating due to painful swallowing. In the 24 hours following admission her condition progressively worsened and she was witnessed aspirating. She was moved to the ICU for intubation and mechanical ventilation due to worsening hypoxemia. She was diagnosed with ARDS secondary to aspiration pneumonia. Chest radiograph after intubation revealed dense bilateral infiltrates consistent with edema. Arterial blood analysis showed severe hypoxemia on lung-protective ventilation per the ARDS Network protocol (Table 1). Initial management included low- $\mathrm{V}_{\mathrm{T}}(6-8 \mathrm{~mL} / \mathrm{kg} \mathrm{PWB})$, volume control continuous mandatory ventilation, incremental PEEP titrations to $15 \mathrm{~cm} \mathrm{H}_{2} \mathrm{O}$, and plateau pressure not exceeding $30 \mathrm{~cm} \mathrm{H}_{2} \mathrm{O}$. Her predicted body weight was calculated with the equation:

$$
\text { PBW }(\mathrm{kg})=45.5+2.3 \text { (height (in) }-60)
$$

Difficulties in oxygenation and a deteriorating medical condition resulted in a change to pressure control continuous mandatory ventilation, while ensuring low- $\mathrm{V}_{\mathrm{T}}$ ventilation, and, ultimately, transfer to our facility 48 hours after intubation.

Upon arrival the patient was cyanotic, with $\mathrm{S}_{\mathrm{pO}_{2}}$ of $54 \%$. Additional problems included hypovolemia, probable septic shock, and acute renal failure. Medical interventions at this time included sedation and a neuromuscular blocking agent, fluid boluses to maintain a minimum central venous pressure of $4-8 \mathrm{~mm} \mathrm{Hg}, 7,8$ and vasopressors to maintain a mean arterial pressure of $\geq 65 \mathrm{~mm} \mathrm{Hg}$. Steroids were not given, because her baseline cortisol level was $31.6 \mu \mathrm{g} / \mathrm{dL}$.

Our modification of the initial ventilation strategy (pressure control continuous mandatory ventilation with $\mathrm{V}_{\mathrm{T}}$ of $6 \mathrm{~mL} / \mathrm{kg}$ PBW) included incorporation of alveolar recruitment maneuvers with PEEP adjustments based on a quasistatic P-V curve and decremental PEEP trials. Key points on the P-V curve include the lower inflection point, the additional recruitable volume (identified during the inspiratory pause), and the point of maximum hysteresis, which is the largest volume difference between the inspiratory and expiratory curves. These procedures were performed as follows.

Soon after the patient was admitted to our ICU, we generated an automated, low-flow quasi-static P-V curve, using the PV Tool II on the Galileo ventilator (Hamilton Medical, Bonaduz, Switzerland). Automated P-V curves are also commercially available on the Viasys Avea and Dräger Evita XL ventilators. In the absence of automated 


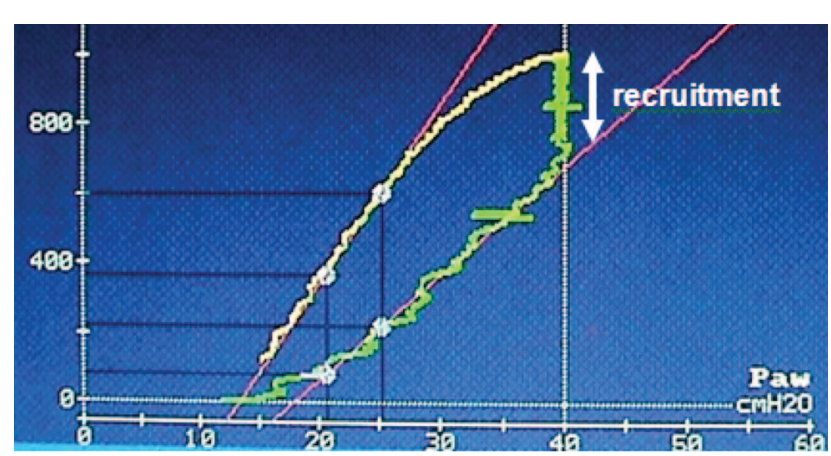

Fig. 1. Initial airway pressure $\left(P_{\text {aw }}\right)$ versus volume curve, beginning from a baseline PEEP of $15 \mathrm{~cm} \mathrm{H}_{2} \mathrm{O}$, increasing to a recruiting pressure of $40 \mathrm{~cm} \mathrm{H} \mathrm{H}_{2} \mathrm{O}$. Pressure is automatically increased by $3 \mathrm{~cm} \mathrm{H}_{2} \mathrm{O}$ per second during the maneuver. The inspiratory curve is green. The expiratory curve is yellow. The red lines indicate the inspiratory and expiratory chord compliance through the white points on the curves.

P-V curves, one can use any commercially available ventilator to perform this, as previously described. ${ }^{9}$ The maneuver was performed beginning from a baseline PEEP of $15 \mathrm{~cm} \mathrm{H}_{2} \mathrm{O}$, increasing to a recruiting pressure of $40 \mathrm{~cm} \mathrm{H}_{2} \mathrm{O}$, followed by a decrease to baseline PEEP. A recruiting pressure of $40 \mathrm{~cm} \mathrm{H}_{2} \mathrm{O}$ was chosen because of: a suspicion of stiff chest wall mechanics due to her obesity; our understanding of previously reported literature, which suggested the safe use of such recruiting pressures with minimal adverse hemodynamic effects ${ }^{10-15}$; and limiting the recruitment $\mathrm{V}_{\mathrm{T}}$ to around $1,000 \mathrm{~mL}$, based on static compliance, which we calculated as:

Static compliance $24 \mathrm{~mL} / \mathrm{cm} \mathrm{H}_{2} \mathrm{O} \times 40 \mathrm{~cm} \mathrm{H}_{2} \mathrm{O}$

$=960 \mathrm{~mL}$ expected recruited volume

We also used an end-inspiratory pause of 23 seconds during the maneuver, for a total maneuver time of $40 \mathrm{sec}-$ onds (Fig. 1). The pressure is automatically increased by $3 \mathrm{~cm} \mathrm{H}_{2} \mathrm{O}$ per second during the maneuver (other ventilators control flow rather than pressure during automated P-V curve maneuvers). ${ }^{16}$ In Figure 1 the inspiratory curve is shown in green and the expiratory curve in yellow. The red lines indicate inspiratory and expiratory chord compliances through the white points on the curves. The inspiratory curve compliance was $24 \mathrm{~mL} / \mathrm{cm} \mathrm{H}_{2} \mathrm{O}$. The expiratory curve compliance was $44 \mathrm{~mL} / \mathrm{cm} \mathrm{H}_{2} \mathrm{O}$. The white points were chosen in order to superimpose the red lines over the linear slopes of the curves, to identify the point at which the curve's trajectory deviates from the red lines. This deviation can be interpreted as the pressure at which alveolar behavior changes, indicating recruitment or derecruitment. The black lines project off of the white dots to indicate values of both pressure and volume.

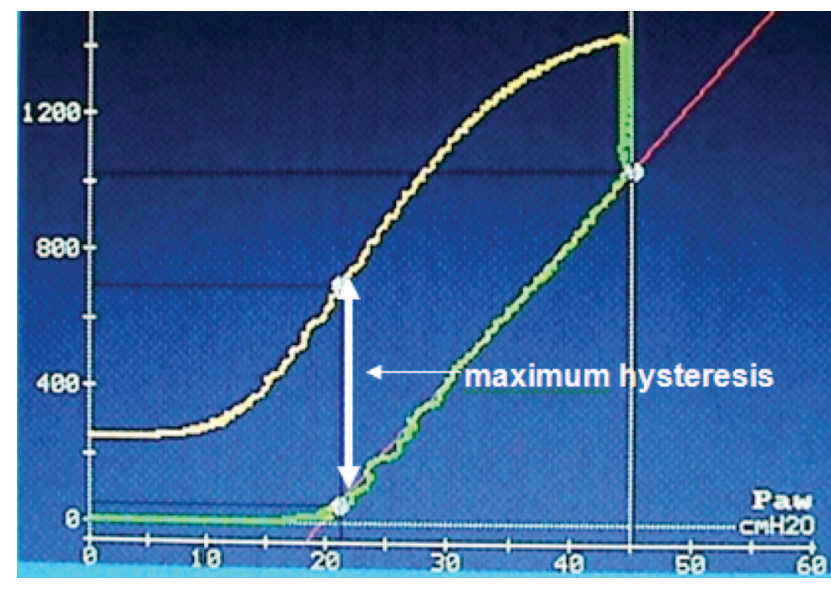

Fig. 2. Second airway pressure $\left(P_{a w}\right)$ versus volume curve, beginning from a baseline PEEP of $0 \mathrm{~cm} \mathrm{H}_{2} \mathrm{O}$ increasing to a recruiting pressure of $45 \mathrm{~cm} \mathrm{H}_{2} \mathrm{O}$. The pressure-volume curve hysteresis is greatest around $22 \mathrm{~cm} \mathrm{H}_{2} \mathrm{O}$.

The point of maximum hysteresis, as described by Demory et $\mathrm{al}^{3}$ and Koefoed-Neilsen et al, ${ }^{17}$ was initially observed to be greatest around $30-35 \mathrm{~cm} \mathrm{H}_{2} \mathrm{O}$, but was thought to be high because of performing the maneuver at a PEEP of $15 \mathrm{~cm} \mathrm{H}_{2} \mathrm{O}$. However, there was an increase in end-inspiratory recruitable volume of greater than $300 \mathrm{~mL}$ (white arrow in Fig. 1). Recruitment is observed as an increase in lung volume (vertical green line) at the endinspiratory hold $\left(40 \mathrm{~cm} \mathrm{H}_{2} \mathrm{O}\right)$. The fact that this particular maneuver is a pressure controller rather than a flow controller allows volume to accumulate in this manner at constant pressure if recruitable lung is available. $\mathrm{S}_{\mathrm{pO}_{2}}$ increased immediately after the maneuver, from $54 \%$ to $75 \%$, with the previous ventilator settings ( $\mathrm{PEEP} 15 \mathrm{~cm} \mathrm{H}_{2} \mathrm{O}, \mathrm{F}_{\mathrm{IO}_{2}} 1.0$ ), but over the subsequent 2 minutes $\mathrm{S}_{\mathrm{pO}_{2}}$ decreased to $70 \%$.

A second recruitment maneuver was performed, with an end-inspiratory pause of 20 seconds and a recruiting pressure to $45 \mathrm{~cm} \mathrm{H}_{2} \mathrm{O}$ (Fig. 2). A start and end pressure of $0 \mathrm{~cm} \mathrm{H}_{2} \mathrm{O}$ was used to obtain a better analysis of the alveolar pressures at which recruitment and derecruitment occurred. Following the second recruitment maneuver, $\mathrm{S}_{\mathrm{pO}_{2}}$ improved to $93 \%$, still with the prior ventilator settings. Analysis of the P-V curve indicated that the point of maximum hysteresis was an alveolar pressure of approximately $22 \mathrm{~cm} \mathrm{H}_{2} \mathrm{O}$ (see Fig. 2), indicating a potential optimal PEEP. During the subsequent $15 \mathrm{~min}$, with a PEEP of $15 \mathrm{~cm} \mathrm{H} 2 \mathrm{O}, \mathrm{S}_{\mathrm{pO}_{2}}$ decreased from $93 \%$ to $88 \%$, again suggesting alveolar derecruitment.

A third recruitment maneuver was performed with pressure control continuous mandatory ventilation, a PEEP of $45 \mathrm{~cm} \mathrm{H}_{2} \mathrm{O}$, and an inspiratory pressure of $5 \mathrm{~cm} \mathrm{H}_{2} \mathrm{O}$ (ie, peak airway pressure $50 \mathrm{~cm} \mathrm{H}_{2} \mathrm{O}$ ), for 45 seconds. This maneuver was simply done to re-recruit alveoli that had collapsed as a result of persistently setting the PEEP at $15 \mathrm{~cm} \mathrm{H}_{2} \mathrm{O}$ following the recruitment maneuvers. The in- 
spiratory-time setting was set long enough to allow inspiratory flow to decay to zero, which allowed for the safe assumption that plateau pressure was equal to peak airway pressure. $\mathrm{S}_{\mathrm{pO}_{2}}$ immediately increased to $99 \%$. This response suggested the potential for a higher PEEP setting. To minimize potential de-recruitment of newly opened lung units, we proceeded with a decremental PEEP maneuver. Thus, with the inspiratory pressure remaining at $5 \mathrm{~cm} \mathrm{H}_{2} \mathrm{O}$, PEEP was decreased in $5 \mathrm{~cm} \mathrm{H}_{2} \mathrm{O}$ increments every minute, down to a PEEP of $22 \mathrm{~cm} \mathrm{H}_{2} \mathrm{O}$.

Hemodynamic variables (heart rate and blood pressure) were stable prior to and remained unchanged during and after all the recruitment maneuvers. Following the final PEEP adjustment, inspiratory pressure was increased to $13 \mathrm{~cm} \mathrm{H}_{2} \mathrm{O}$ to restore $\mathrm{V}_{\mathrm{T}}$ to $6 \mathrm{~mL} / \mathrm{kg}$ PBW. Peak airway pressure was $35 \mathrm{~cm} \mathrm{H}_{2} \mathrm{O}$, with inspiratory flow decaying to zero, indicating pressure equilibration between circuit and alveolar pressure. An inspiratory hold confirmed that plateau pressure was indeed $35 \mathrm{~cm} \mathrm{H}_{2} \mathrm{O} . \mathrm{S}_{\mathrm{pO}_{2}}$ was sustained at $99 \%$ throughout the PEEP titrations. Within the next 4 hours we reduced $\mathrm{F}_{\mathrm{IO}_{2}}$ to 0.7 with $\mathrm{S}_{\mathrm{pO}_{2}}$ remaining above $99 \%$. Serial chest radiographs showed improved aeration. During the next 48 hours further $\mathrm{F}_{\mathrm{IO}_{2}}$ reductions were achieved and PEEP was decreased based on serial $\mathrm{P}-\mathrm{V}$ curves (see Table 1). The patient was successfully extubated on day 5 after arrival at our facility, and was discharged from the hospital on day 19.

\section{Discussion}

This case demonstrates how several ventilation strategies can be woven together in the face of a deteriorating clinical condition. These interventions are not generally recommended for routine use, and should be given careful consideration. Although there are data in the literature regarding each of these techniques (none of which show a survival benefit), there are no studies comparing these various tactics to one another for management of severe hypoxemia. In contrast, if used appropriately, they can assist in individualizing the ventilator settings to the patient's lung mechanics, while providing lung protection. Culturally, we have incorporated the ARDS Network protocol into clinical practice because it decreases mortality ${ }^{1}$ and provides simplicity that helps reduce ALI/ARDS practice variation. However, clinicians, at times, are reluctant to consider alternative approaches if desirable goals are not met within the protocol. In particular, most clinicians rely solely on lung-protective ventilation and the ARDS Network $\mathrm{PEEP} / \mathrm{F}_{\mathrm{IO}_{2}}$ table, but in some cases, simply raising the $\mathrm{F}_{\mathrm{IO}_{2}}$ and/or PEEP are not adequate to improve oxygenation, which warrants the use of other tactics. Tactics in addition to those we used in the patient described above include prone positioning, inhaled vasodilators, highfrequency ventilation, and PEEP guided by esophageal manometry. We did not consider the latter tactics in the patient described above, because they require additional personnel or equipment, whereas the tactics we used did not. This case study demonstrates how analysis of an automated P-V curve, followed by recruitment maneuvers, a decremental PEEP strategy, and a $\mathrm{V}_{\mathrm{T}}$ of $6 \mathrm{~mL} / \mathrm{kg}$ PBW while allowing plateau pressure to exceed $30 \mathrm{~cm} \mathrm{H}_{2} \mathrm{O}$ because of obesity-related stiff chest wall mechanics, were used to safely individualize the ventilation care plan while providing lung protection and restoring normoxia.

The ventilation strategy for ARDS has changed over the last decade. The focus has shifted from normalizing the arterial blood gas values with high $\mathrm{V}_{\mathrm{T}}$, to a strategy that minimizes both alveolar stretch due to excessive $\mathrm{V}_{\mathrm{T}}$ (volutrauma) and the repetitive opening and collapse of diseased alveoli (atelectrauma). This approach aims to reduce inflammatory cytokine and neutrophil elastase production (biotrauma). ${ }^{18}$ The first focus has been addressed with reduced $\mathrm{V}_{\mathrm{T}}$ and plateau pressure, whereas the second may be achieved with the use of recruitment maneuvers to open collapsed lung units, and high PEEP. ${ }^{6}$

Several methods for performing recruitment maneuvers exist, ${ }^{13-15,19,20}$ but, without computed tomography, most fail to use the pressure-volume relationship of the lung to quantify lung recruitability and/or lung de-recruitment. ${ }^{10}$ Demory and colleagues in a "preliminary and exploratory" study, used quasi-static P-V curves to estimate lung recruitability. ${ }^{3}$ They found a significant relationship between the maximum hysteresis (the difference between the inspiratory and expiratory volumes at a given alveolar pressure) and the volume increase during a recruitment maneuver. Koefoed-Nielsen also found, in a porcine lung injury model, that PEEP set at $90 \%$ of maximum hysteresis gave similar oxygenation, higher quasi-static compliance of the respiratory system, fewer hyperaerated areas, and less cardiovascular depression than did PEEP set at the lower inflection point or the point of maximum curvature. ${ }^{17}$ This relationship, if confirmed, may assist in identifying patients who would benefit from a recruitment maneuver. However, careful consideration should be given to the use of recruitment maneuvers, because in certain patients they may be poorly tolerated (hemodynamic instability, pulmonary emphysema). The P-V curves from our patient indicated the potential benefits of a recruitment maneuver followed by a modified decremental PEEP strategy. Also, further assessment of Figures 1 and 2 shows a commonality that may explain why our patient persistently de-recruited on PEEP of $15 \mathrm{~cm} \mathrm{H}_{2} \mathrm{O}$ following the recruitment maneuvers. Despite the end-exhalation pressure at which the recruitment maneuvers began (zero vs $15 \mathrm{~cm} \mathrm{H}_{2} \mathrm{O}$ ), initial recruitment is not observed until alveolar pressure exceeds $17-18 \mathrm{~cm} \mathrm{H}_{2} \mathrm{O}$, in both curves. Prior to each recruitment maneuver we analyzed the expiratory flow pattern and performed a manual expiratory 
hold to assess for intrinsic PEEP, and found no intrinsic PEEP, so this could represent the chest wall pressure that must be overcome to recruit alveoli. Therefore, if the endexpiratory alveolar pressure falls below $17-18 \mathrm{~cm} \mathrm{H}_{2} \mathrm{O}$, alveoli may be unable to sustain persistent opening, leading to VILI and worsening hypoxemia.

Hickling ${ }^{4}$ and Girgis et $\mathrm{al}^{5}$ have proposed that PEEP should be set in a decremental fashion following lung recruitment. This method is simply a PEEP trial that adjusts PEEP from a higher level to a lower level. ${ }^{5}$ The minimum PEEP is the PEEP required to maintain the oxygenation benefit of the recruitment maneuver. Minimum PEEP maintains the lung above the point of maximum hysteresis on the deflation part of the P-V curve. During the initial care of our patient we observed desaturation each time the PEEP was restored to $15 \mathrm{~cm} \mathrm{H}_{2} \mathrm{O}$ following the recruitment maneuver, which suggests lung derecruitment due to decreased end-expiratory alveolar pressure. We performed a modified decremental PEEP trial, decreasing PEEP by $5 \mathrm{~cm} \mathrm{H}_{2} \mathrm{O}$ every minute, down to a PEEP of $22 \mathrm{~cm} \mathrm{H}_{2} \mathrm{O}$ (based on P-V curve hysteresis).

A recent approach demonstrated significant improvement in oxygenation and static lung compliance using esophageal pressure (measured via esophageal balloon) to guide PEEP adjustment to minimize end-expiratory transpulmonary pressure. ${ }^{21}$ This method was not initially considered in our patient, because we wanted to minimize the number of invasive procedures (eg, placement of esophageal balloon) until she was medically stable, and at the time we were unaware of studies on the association of esophageal pressure and lung recruitability. $\mathrm{V}_{\mathrm{T}}$ of $6 \mathrm{~mL} / \mathrm{kg}$ PBW was restored after the decremental PEEP process, resulting in a plateau pressure of $34-35 \mathrm{~cm} \mathrm{H}_{2} \mathrm{O}$. Figure 3 illustrates our algorithm.

Acceptance of a plateau pressure exceeding $30 \mathrm{~cm} \mathrm{H}_{2} \mathrm{O}$ appeared appropriate in our patient. Recently, Meade et $\mathrm{al}^{6}$ examined the mortality effect of an open-lung approach that combines $\mathrm{V}_{\mathrm{T}}$, recruitment maneuvers, high PEEP, and plateau pressure less than $40 \mathrm{~cm} \mathrm{H}_{2} \mathrm{O}$, compared to an established low- $\mathrm{V}_{\mathrm{T}}$ ventilation strategy in patients with moderate to severe lung injury. They found an equivalent mortality rate, but the open-lung strategy was better in secondary end points, related to hypoxemia and fewer rescue therapies. For our patient we perceived that approach as acceptable because of an established understanding that, at times, plateau pressure and $\mathrm{V}_{\mathrm{T}}$ are not primary surrogates for lung stress and strain. ${ }^{22}$ Maximum tidal transalveolar pressure (stress), and actual tissue stretch (strain) are the primary cause of VILI. Talmor et $\mathrm{a}^{21}$ used esophageal-pressure-guided PEEP for ARDS management. Despite the finding that plateau pressure reached as high as $35 \mathrm{~cm} \mathrm{H}_{2} \mathrm{O}$, end-inspiratory $\mathrm{P}_{\mathrm{tp}}$ never exceeded $24 \mathrm{~cm} \mathrm{H}_{2} \mathrm{O}$ and did not differ significantly from the control group. This suggests that alveolar stress may remain tolerable

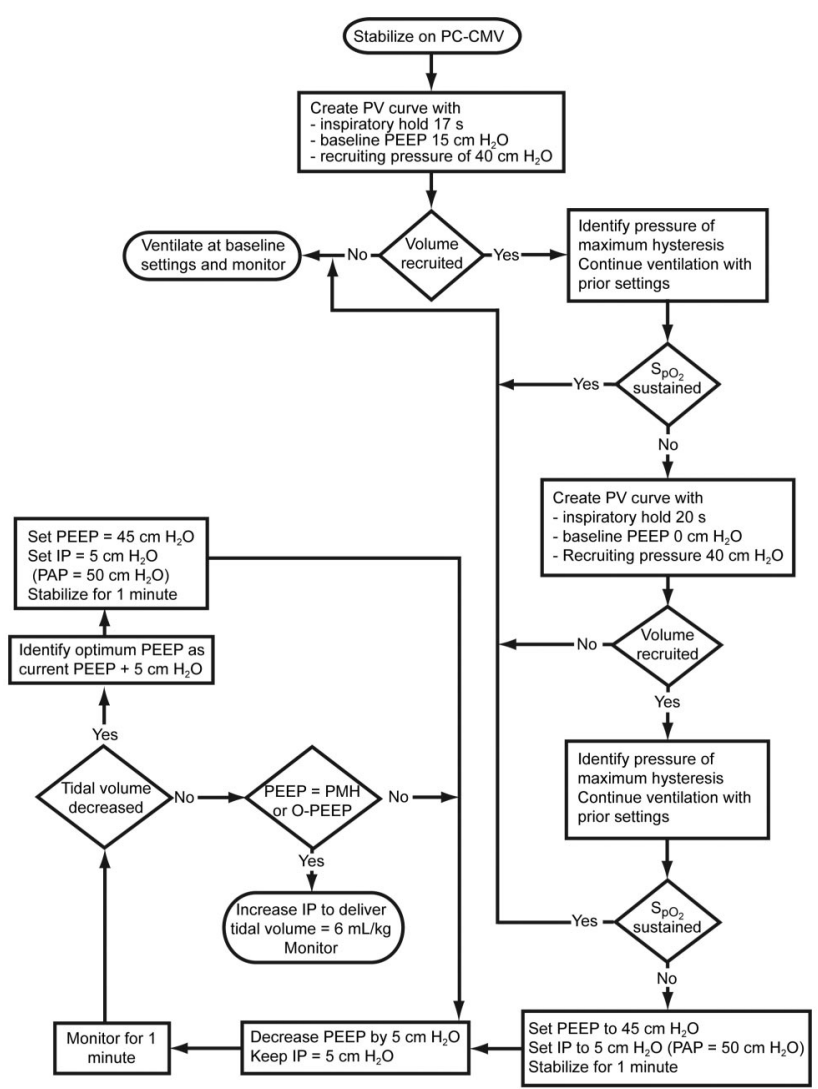

Fig. 3. The PEEP optimization algorithm we used with this patient. $\mathrm{PC}-\mathrm{CMV}=$ pressure control continuous mandatory ventilation. $\mathrm{PV}=$ pressure-volume. IP = inspiratory pressure above PEEP, $\mathrm{O}-\mathrm{PEEP}=$ optimum PEEP, $\mathrm{PMH}=$ pressure of maximum hysteresis. PAP $=$ peak airway pressure.

despite increasing plateau and pleural pressure generated by an opposing stiff chest wall.

Although the ARDS Network protocol was designed to streamline our approach to ventilating ARDS patients, and has a survival benefit, it does not discourage the use of rescue therapies in life-threatening situations. The tactics discussed above improved our patient's oxygenation while minimizing VILI. These tactics are not recommended for routine use, because no evidence of a mortality benefit has been demonstrated. Careful consideration of clinical indications and contraindications must be given to their application. However, if carefully utilized, they can provide additional information for individualizing the ventilator settings to safely oxygenate and ventilate a patient in relation to the patient's lung mechanics. At present, these rescue therapies should remain as alternatives until the patient's clinical picture warrants their use.

\section{REFERENCES}

1. The Acute Respiratory Distress Syndrome Network. Ventilation with lower tidal volumes as compared with traditional tidal volumes for 


\section{Customization of an Open-Lung Ventilation Strategy for ARDS}

acute lung injury and the acute respiratory distress syndrome. $\mathrm{N}$ Engl J Med 2000;342(18):1301-1308.

2. Bernard GR, Artigas A, Brigham KL, Carlet J, Falke K, Hudson L, et al. The American-European consensus conference on ARDS: definitions, mechanisms, relevant outcomes, and clinical trial coordination. Am J Respir Crit Care Med 1994;149(3 Pt 1):818-824.

3. Demory D, Arnal J-M, Wysocki M, Donati S, Granier I, Corno Gaelle, Durand-Gaselin J. Recruitability of the lung estimated by the pressure volume curve hysteresis in ARDS. Intensive Care Med 2008;34(11):2019-2025.

4. Hickling KG. Best compliance during a decremental, but not incremental, PEEP trial is related to open-lung PEEP: a mathematical model of acute respiratory distress syndrome lungs. Am J Respir Crit Care Med 2001;163(1):69-78.

5. Girgis K, Hamed H, Khater Y, Kacmarek R. A decremental PEEP trial identifies the PEEP level that maintains oxygenation after lung recruitment. Respir Care 2006;51(10):1132-1139.

6. Meade M, Cook D, Guyatt G, Slutsky A, Arabi Y, Cooper D, et al. Ventilation strategy using low tidal volumes, recruitment maneuvers, and high PEEP for acute lung injury and acute respiratory distress syndrome. JAMA 2008;299(6):637-645.

7. Wheeler AP, Bernard GR, Thrompson B, Schoenfeld D, Wiedemann HP, de Boisblanc B, et al; National Heart, Lung, and Blood Institute; ARDS Clinical Trials Network. Pulmonary-artery versus central venous catheter to guide treatment of acute lung injury. N Engl J Med 2006;354(21):2213-2224.

8. Wiedemann HP, Wheeler AP, Bernard GR, Thompson BT, Hayden D, de Boisblanc B, et al; National Heart, Lung, and Blood Institute; ARDS Clinical Trials Network. Comparison of 2 fluid-management strategies in acute lung injury. N Engl J Med 2006;354(24):25642575.

9. Amato MBP, Barbas CSV, Medeiros DM, Schettino P, LorenziFilho G, Kairalla RA, et al. Beneficial effects of the "open lung approach" with low distending pressures in acute respiratory distress syndrome: a prospective randomized study on mechanical ventilation. Am J Respir Crit Care Med 1995;152(6):1835-1846.

10. Barbas CS. Lung recruitment manuevers in acute respiratory distress syndrome and facilitating resolution. Crit Care Med 2003;31(4): S265-S271.

11. Lim SC, Adams AB, Simonson DA, Dries DJ, Broccard AF, Hotchkiss JR, Marini JJ. Intercomparison of recruitment maneuver effi- cacy in 3 models of acute lung injury. Crit Care Med 2004;32(12): 2371-2377.

12. Oczenski W, Hormann C, Keller C, Lorenzi N, Kepka A, Schwarz S, Fitzgerald R. Recruitment Maneuvers after a PEEP trial do not induce sustained effects in early adult respiratory distress syndrome. Anethesiology 2004;101(3):620-625.

13. Tugrul S, Akinci O, Ozcan P, Ince S, Esen F, Telci L, et al. Effects of sustained inflation and postinflation PEEP in acute respiratory distress syndrome: focusing on pulmonary and extrapulmonary forms. Crit Care Med 2003;31(3):738-744.

14. Borges JB, Okamoto VN, Matos GF, Caramez MP, Arantes PR, Barros F, et al. Reversibility of lung collapse and hypoxemia in early acute respiratory distress syndrome. Am J Respir Crit Care Med 2006;174(3):268-278.

15. Gatinoni L, Caironi P, Cressoni M, Chiumello D, Ranieri M, Quintel $\mathrm{M}$, et al. Lung recruitment in patients with the acute respiratory distress syndrome. N Engl J Med 2006;354(17):1775-1786.

16. Piacenti E, Wysocki M, Blanch L. A new automated method versus continuous positive airway pressure method for measuring pressurevolume curves in patients with acute lung injury. Intensive Care Med 2009;35(3):565-570

17. Koefoed-Neilsen J, Andersen G, Barklin A, Bach A, Lunde S, Tonnesen E, et al. Maximal hysteresis: a new method to set PEEP in acute lung injury. Acta Anaesthesiol Scand 2008;52(5):641-649.

18. Slutsky A. Ventilator induced lung injury: from barotrauma to biotrauma. Respir Care 2005;50(5):646-659.

19. Grasso S, Mascia L, Del Turco M, Malacarne P, Giunta F, Brochard $\mathrm{L}$, et al. Effects of recruiting maneuvers in patients with acute respiratory distress syndrome ventilated with protective ventilatory strategy. Anesthesiology 2002;96(4):795-802.

20. Lapinsky SE, Aubin M, Mehta S, Boiteau P, Slutsky AS. Safety and efficacy of a sustained inflation for alveolar recruitment in adults with respiratory failure. Intensive Care Med 1999;25(11):1297-1301.

21. Talmor D, Sarge T, Malhotra A, O'Donnell C, Ritz R, Lisbon A, et al. Mechanical ventilation guided by esophageal pressure in acute lung injury. N Engl J Med;359(20):2095-2104.

22. Chiumello D, Carlesso E, Cadringer P, Caironi P, Valenze F, Polli F, et al. Lung stress and strain during mechanical ventilation for acute respiratory distress syndrome. Am J Respir Crit Care Med 2008; 178(4):346-355. 